\section{BMJ Open Respiratory Research}

\title{
Association of sleep apnoea risk and aortic enlargement in Marfan syndrome
}

\author{
Mudiaga Sowho, ${ }^{1}$ Gretchen MacCarrick, ${ }^{2}$ Harry Dietz, ${ }^{2}$ Jonathan Jun, ${ }^{1}$ \\ Alan R Schwartz, ${ }^{3}$ Enid R Neptune ${ }^{1}$
}

To cite: Sowho M, MacCarrick G, Dietz H, et al. Association of sleep apnoea risk and aortic enlargement in Marfan syndrome. BMJ Open Resp Res 2021;8:e00942. doi:10.1136/ bmjresp-2021-000942

Received 29 March 2021 Accepted 19 October 2021
Check for updates

(c) Author(s) (or their employer(s)) 2021. Re-use permitted under CC BY-NC. No commercial re-use. See rights and permissions. Published by BMJ.

${ }^{1}$ Division of Pulmonary and Critical Care Medicine, Johns Hopkins School of Medicine, Baltimore, Maryland, USA

${ }^{2}$ McKusick-Nathans Institute of Genetic Medicine, Johns Hopkins School of Medicine, Baltimore, Maryland, USA

${ }^{3}$ Otolaryngology, University of Pennsylvania Perelman School of Medicine, Philadelphia, Pennsylvania, USA

Correspondence to Dr Mudiaga Sowho; msowho1@jhmi.edu

\section{ABSTRACT}

Background Marfan syndrome (MFS) is a connective tissue disorder characterised by complex aortic pathology and a high prevalence of obstructive sleep apnoea (OSA). OSA produces intrathoracic transmural stresses that may accelerate aortic injury. The current study was designed to examine the associations between OSA risk and markers of aortic enlargement in MFS.

Method Consecutive patients with MFS were recruited at Johns Hopkins if they completed a STOP-BANG survey. Composite survey scores were categorised into those with low OSA risk (STOP-BANG $<3$ ) and high OSA risk (STOP-BANG $\geq 3$ ). Participants' aortic data were collated to ascertain aortic root diameter, dilatation and prior aortic root replacement. Regression analyses were used to examine associations between OSA risk strata and these aortic parameters.

Results Of the 89 participants studied, $28 \%$ had a high OSA risk and $32 \%$ had aortic grafts. Persons with high OSA risk had greater aortic root diameter $(\mathrm{mm})(B=4.13$, $\mathrm{SE}=1.81, p=0.027)$ and aortic root dilatation $(B=2.80$, $\mathrm{SE}=1.34, \mathrm{p}=0.046$ ) compared with those with low 0SA risk . In addition, the odds of prior aortic root replacement was three times greater in those with high OSA risk compared with those with low OSA risk.

Conclusion In MFS, high OSA risk is associated with aortic enlargement and a threefold increased risk of having had prior aortic root replacement. These findings invite further exploration of the relationship between OSA and aortic disease in MFS, and studies to clarify whether targeted interventions for OSA might mitigate aortic disease progression in MFS.

Registration number IRB00157483.

\section{INTRODUCTION}

Marfan syndrome (MFS) is a single gene disorder of connective tissue resulting in a structurally defective aortic wall, with consequent cardiovascular complications such as aortic aneurysm and dissection at a young age. ${ }^{12}$ Current management includes the use of beta-blockers and angiotensin receptor blockers (ARBs) to mitigate haemodynamic stress and prevent pathological enlargement of the aorta. Despite use of these medications, persons with MFS remain at elevated risk for aortic dissection and rupture, and sometimes require surgical intervention. ${ }^{3-5}$
Key messages

Does screening with the STOP-BANG questionnaire provide a method to identify persons with Marfan syndrome (MFS) at risk of aortic enlargement in the setting of obstructive sleep apnoea therefore meriting referral for formal sleep studies?

- Early detection and treatment of obstructive sleep apnoea in the MFS population may mitigate aortic disease progression.

- This is the first study to offer a simple means for the early identification of persons with MFS with a high risk for aortic enlargement in the setting of untreated obstructive sleep apnoea.

Obstructive sleep apnoea (OSA) is a recognised source of both haemodynamic and mechanical stress and is highly prevalent in MFS. ${ }^{6-9}$ OSA is characterised by periods of upper airway obstruction (UAO) during sleep punctuated by increased sympathetic activity leading to elevations in blood pressure and pulse rate. $^{10}$ Furthermore, large swings in intrathoracic pressure that occur during these obstructive breathing events and concomitant snoring ${ }^{11}$ plausibly exert dilatory stress on the aorta. ${ }^{12}$ A case report by Cistulli $e t$ al, demonstrated reduced aortic dilatation in a patient with MFS after treatment of OSA with continuous positive airway pressure. ${ }^{13}$ However, studies exploring the relationship between OSA and aortic enlargement in MFS are lacking.

The present study examines cross-sectional associations between OSA risk and markers of aortic enlargement in persons with MFS. We hypothesised that a high risk for OSA would be positively associated with aortic root size and aortic root dilatation. We further hypothesised that high risk for OSA would be associated with prior aortic root replacement, a common surgical result of progressive dilatation.

\section{METHODS}

\section{Patient and public involvement}

Our research question was based on the premise that aortic disease is the most common cause of death in the MFS population, and 


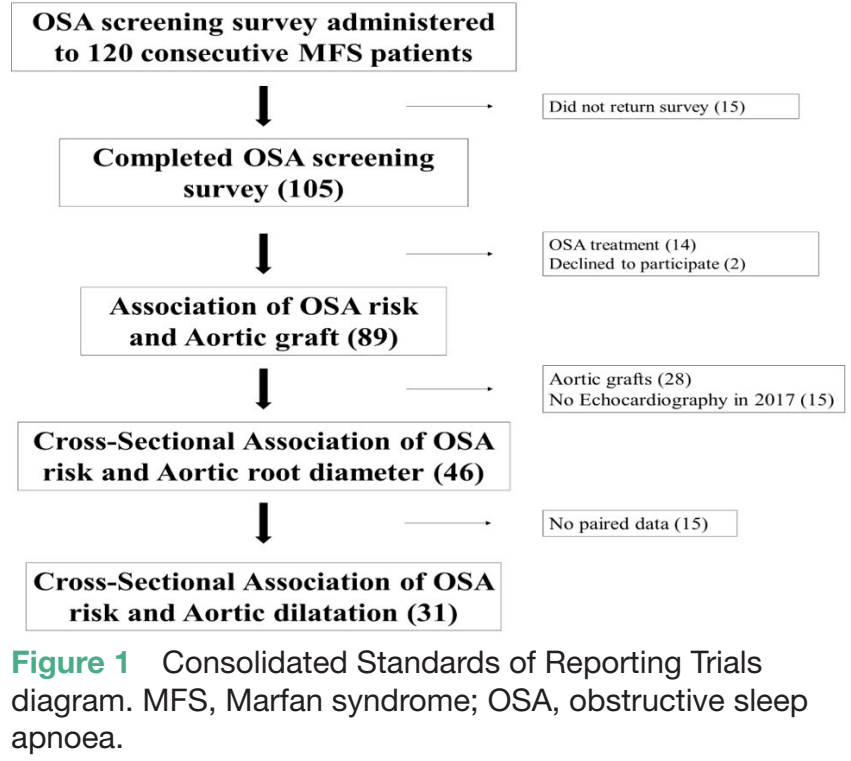

that OSA, a common disorder in this population, may contribute to aortic morbidity. ${ }^{9} 14$ Participants were recruited as part of a cross-sectional OSA risk survey conducted at the Johns Hopkins Connective Tissues Disorders' Clinic, Baltimore, Maryland, from December 2017 to December 2019. Consecutive patients visiting the clinic for yearly health status evaluation received an OSA screening survey and completed it if they consented to participating. Eligible persons were adults over the age of 18 with genetic characterisation of fibrillin 1 ( $F B N-1)$ mutation, and those who were on OSA treatment were excluded (figure 1).

Demographic and anthropometric information were collected along with echocardiography data, which were accessed from the electronic medical record system. Our findings will be disseminated to participants via electronic mail information provided at the time of recruitment.

\section{Specific procedures}

\section{Anthropometry}

Participants had their height, weight and neck circumference taken using standard techniques. ${ }^{15}$ Height and weight measurements were used to calculate body mass index (BMI).

\section{Questionnaires}

The STOP-BANG screening survey ${ }^{16}$ was administered during the routine clinic visits between 2017 and 2019. Survey scores were used to group participants into low risk (STOP-BANG <3) or high risk for OSA (STOPBANG $\geq 3$ ) categories. Loud snoring, tiredness, witnessed apnoeas and hypertension were determined by yes or no responses on the STOP-BANG questionnaire.

\section{Aortic dimensions}

Transthoracic echocardiograms were performed and read by highly experienced cardiologists. Aortic root diameter was measured as previously described ${ }^{17}$ at endsystole by the inner-edge convention in the parasternal long-axis view that showed the maximum diameter parallel to the aortic annular plane. Aortic root diameter measurements in 2017 were used for the cross-sectional analyses and aortic root dilatation was calculated by subtracting subjects' aortic root diameter in 2013 from that in 2017. These dates span the data acquisition time points approved for the study.

\section{Statistical analyses}

To test our primary hypothesis, we used linear regression to model the association between OSA risk strata as the independent variable and aortic root diameter as well as aortic root dilatation as the outcome. We further investigated the associations between each OSA risk factor in the STOP-BANG (loud snoring, tiredness, witnessed apnoeas, hypertension, BMI, age, neck size, sex) and aortic dimensions using univariable linear regression analyses. Since grafting, a possible result of dilatation was more common in the older subjects; we further examined the association between OSA risk and aortic root dilatation in groups stratified by the median age.

Our secondary hypothesis was that high OSA risk would be associated with aortic root replacement, the major intervention for progressive dilatation in MFS. To test this hypothesis, we used logistic regression to model the association between OSA risk strata as the independent variable and aortic root replacement as the outcome. We also further examined the associations between each OSA risk factor in the STOP-BANG (loud snoring, tiredness, witnessed apnoeas, hypertension, BMI, age, neck size, sex) and aortic root replacement.

Analyses were performed using R (www.r-project.org, with the regression models using the 'stats' package) and a two-sided $\mathrm{p}<0.05$ was considered statistically significant.

\section{RESULTS}

\section{Participant characteristics}

After screening, we enrolled 89 participants including 28 who had prior aortic replacement surgery. As shown in table 1 , men comprised $60 \%$ of the group and the median BMI was within the normal range. Based on STOP-BANG questionnaire responses, $28 \%$ had a high risk of OSA and median STOP-BANG score was two. The group with a high OSA risk was older, had a higher proportion of men, a greater BMI and neck size as expected for a group with suspected OSA. There was also a higher proportion of loud snorers, persons with hypertension, reported tiredness and witnessed apnoeas in the high OSA risk group (table 1). Eighty-five per cent of subjects were on a betablocker, ARB or a combination of both. Continuous data are presented as median with the IQR in parenthesis.

Forty-six participants had aortic root diameter measurements at baseline (2017) and 31 participants had paired measurements (2013-2017). The characteristics of these subsets of participants are shown in table 2. 


\begin{tabular}{|c|c|c|c|}
\hline & All participants $(n=89)$ & High OSA risk $(n=25)$ & Low OSA risk $(n=64)$ \\
\hline \multicolumn{4}{|l|}{ Demographics } \\
\hline Men:women & $36: 53$ & $18: 7$ & $18: 46$ \\
\hline Age, years & $35(24-50)$ & $51(33-55)$ & $33(22-42)$ \\
\hline \multicolumn{4}{|l|}{ Anthropometry } \\
\hline BMI, kg/m² & $23.7(21.0-26.7)$ & $25.9(24.4-30.4)$ & $22.5(20.7-25.4)$ \\
\hline Neck, cm & 36.0 (33.9-39.6) & $39.3(38.2-41.6)$ & $35.0(33.5-38.1)$ \\
\hline Body surface area, $\mathrm{m}^{2}$ & $2.0(1.9-2.1)$ & $2.1(2.0-2.3)$ & $2.0(1.9-2.2)$ \\
\hline \multicolumn{4}{|l|}{ STOP-BANG } \\
\hline Loud snoring, n (\%) & $27(30)$ & $16(64)$ & $10(16)$ \\
\hline Witnessed apnoeas, n (\%) & $12(13)$ & $8(32)$ & $3(5)$ \\
\hline Tiredness, n (\%) & $59(65)$ & $21(84)$ & $36(58)$ \\
\hline Hypertension, n (\%) & $20(22)$ & $12(48)$ & $8(13)$ \\
\hline BMI $\left(\geq 35 \mathrm{~kg} / \mathrm{m}^{2}\right), \mathrm{n}(\%)$ & $3(4)$ & $2(8)$ & $1(2)$ \\
\hline Age ( $\geq 50$ years), $n(\%)$ & $23(26)$ & $15(60)$ & $8(13)$ \\
\hline Neck size $(\geq 40 \mathrm{~cm}), \mathrm{n}(\%)$ & $11(12)$ & $5(20)$ & $6(9)$ \\
\hline STOP-BANG score & $2(1-3)$ & $4(3-4)$ & $1.0(1.0-2.0)$ \\
\hline \multicolumn{4}{|l|}{ Aortic grafts } \\
\hline Aortic grafts, n (\%) & $28(31.5)$ & $13(54)$ & $16(26)$ \\
\hline \multicolumn{4}{|l|}{ Blood pressure medication } \\
\hline Beta-blocker only, n (\%) & $10(11)$ & $2(8)$ & $8(13)$ \\
\hline ARB only, n (\%) & $28(31)$ & $7(28)$ & $21(33)$ \\
\hline Beta-blocker and ARB, n (\%) & $37(42)$ & $12(48)$ & $25(39)$ \\
\hline None, $\mathrm{n}(\%)$ & $14(16)$ & $4(16)$ & $10(15)$ \\
\hline
\end{tabular}

Continuous variables are represented as medians with the IQR in parenthesis. Dichotomous variables are represented as a count with the percentage in parenthesis.

ARB, angiotensin receptor blocker; BMI, body mass index; OSA, obstructive sleep apnoea.

\section{Association of OSA risk and aortic root dimensions}

In our MFS cohort, persons with high OSA risk (STOPBANG $\geq 3$ ) had greater aortic root diameter compared to those with low OSA risk $(\beta=4.13, \mathrm{SE}=1.81, \mathrm{p}=0.027)$. Analyses of each STOP-BANG component showed that loud snoring, age and sex were positively associated with aortic root diameter, but neck size, witnessed apnoeas, hypertension and tiredness were not (table 3 ). Of note, BMI $\left(\geq 35 \mathrm{~kg} / \mathrm{m}^{2}\right)$ was negatively associated with aortic root diameter (table 3 ). We further examined BMI as a continuous predictor variable, but found no association with aortic diameter $(\beta=-0.16, \mathrm{SE}=0.16, \mathrm{p}=0.325)$.

Aortic root dilatation was greater in participants with high OSA risk (STOP-BANG $\geq 3$ ) compared with those with low OSA risk $(\beta=2.80, \mathrm{SE}=1.34, \mathrm{p}=0.046)$, but analyses of each STOP-BANG component showed no association between the OSA risk factors and aortic dilatation (table 3). When participants were dichotomised by the median age of the paired subsample, high OSA risk was associated with aortic root dilatation in the group under the median age of 30 years $(\beta=4.00, \mathrm{SE}=1.57, \mathrm{p}=0.024)$ but not in the group above 30 years $(\beta=-0.39, \mathrm{p}=0.511)$. Analyses of each STOP-BANG component in both age group strata (table 4) showed only loud snoring as significantly associated with aortic root dilatation $(\beta=4.00, \mathrm{SE}=1.57$, $\mathrm{p}=0.024)$.

Association of OSA risk and prior aortic root replacement

Participants with high OSA risk had higher odds of having prior aortic root replacement compared with those with low OSA risk $(\mathrm{OR}=4.25,95 \% \mathrm{CI} ; 1.57$ to 11.95 , $\mathrm{p}=0.005$ ). Analyses of each STOP-BANG component showed that only loud snoring $(\mathrm{OR}=2.65,95 \% \mathrm{CI} ; 1.01$ to $7.08, \mathrm{p}=0.048)$, age $\geq 50$ years $(\mathrm{OR}=9.90,95 \% \mathrm{CI} ; 3.47$ to $31.15, \mathrm{p}<0.001)$ and sex $(\mathrm{OR}=3.52,95 \% \mathrm{CI} ; 1.40$ to 9.24 , $\mathrm{p}=0.009$ ) were positively associated with prior aortic root replacement (table 5).

\section{DISCUSSION}

In this retrospective cross-sectional analysis of aortic dimensions in patients with MFS who completed a STOPBANG questionnaire, we found that a high OSA risk was associated with increased aortic root diameter and dilatation rate. Loud snoring, age and male sex were the OSA risk factors associated with aortic diameter, but only loud 
Table 2 Participant characteristics

\begin{tabular}{|c|c|c|c|c|}
\hline & \multicolumn{2}{|l|}{ Subsample (n=46) } & \multicolumn{2}{|c|}{ Paired subsample $(n=31)$} \\
\hline & High OSA risk (8) & Low OSA risk (38) & High OSA risk (4) & Low OSA risk (27) \\
\hline \multicolumn{5}{|l|}{ Demographics } \\
\hline Men:women & $5: 3$ & $11: 27$ & $2: 2$ & $10: 17$ \\
\hline Age, years & $36(20-51)$ & $31(21-39)$ & $25(20-37)$ & $31(21-37)$ \\
\hline \multicolumn{5}{|l|}{ Anthropometry } \\
\hline BMl, kg/m² & $29.2(24.7-31.3)$ & $22.3(20.2-25.1)$ & $25.8(21.4-28.1)$ & $21.5(19.9-25.1)$ \\
\hline Neck, cm & $40.0(38.0-40.3)$ & $35.0(33.6-38.8)$ & $38.0(37.0-39.0)$ & $35.0(33.6-39.3)$ \\
\hline Body surface area, $\mathrm{m}^{2}$ & $2.0(2.0-2.5)$ & $2.0(1.9-2.2)$ & $2.0(1.8-2.0)$ & $2.0(1.9-2.2)$ \\
\hline \multicolumn{5}{|l|}{ STOP-BANG } \\
\hline Loud snoring, n (\%) & $6(75)$ & $4(11)$ & $4(100)$ & $2(7)$ \\
\hline Witnessed apnoeas, n (\%) & $2(25)$ & $2(6)$ & $1(25)$ & $2(7)$ \\
\hline Tiredness, n (\%) & $8(100)$ & $19(53)$ & $4(100)$ & $14(52)$ \\
\hline Hypertension, n (\%) & $4(50)$ & $5(13)$ & $2(50)$ & $5(19)$ \\
\hline BMI $\left(\geq 35 \mathrm{~kg} / \mathrm{m}^{2}\right), \mathrm{n}(\%)$ & $1(14)$ & $1(3)$ & $0(0)$ & $0(0)$ \\
\hline Age ( $\geq 50$ years), $n(\%)$ & $3(38)$ & $2(5)$ & $1(25)$ & $2(7)$ \\
\hline Neck size $(\geq 40 \mathrm{~cm}), \mathrm{n}(\%)$ & $2(25)$ & $3(8)$ & $1(25)$ & $3(11)$ \\
\hline STOP-BANG score & $4.0(3.0-4.0)$ & $1.0(1.0-1.0)$ & $3.5(3.0-4.0)$ & $1.0(1.0-2.0)$ \\
\hline \multicolumn{5}{|l|}{ Aortic parameters } \\
\hline Aortic diameter, mm & $43.3(38.9-45.6)$ & $38.7(35.0-41.1)$ & $43.3(40.6-44.4)$ & $40.0(35.6-41.8)$ \\
\hline Aortic root dilatation, $\mathrm{mm}^{*}$ & - & - & $4.3(0.1-8.6)$ & $1.1(0.2-2.4)$ \\
\hline \multicolumn{5}{|l|}{ Blood pressure medication } \\
\hline Beta-blocker only, n (\%) & $2(25)$ & $5(13)$ & $2(50)$ & $8(30)$ \\
\hline ARB only, n (\%) & $3(37)$ & $10(26)$ & $1(25)$ & $2(7)$ \\
\hline Beta-blocker and ARB, n (\%) & $1(13)$ & $16(42)$ & $1(25)$ & $13(48)$ \\
\hline None, $\mathrm{n}(\%)$ & $2(25)$ & 7 (18) & $0(0)$ & $4(15)$ \\
\hline
\end{tabular}

Continuous variables are represented as medians with the IQR in parenthesis. Dichotomous variables are represented as a count with the percentage in parenthesis.

${ }^{*}$ Aortic dilatation was computed for the subsample with paired aortic data in 2013-2017.

ARB, angiotensin receptor blocker; BMI, body mass index; OSA, obstructive sleep apnoea.

snoring was associated with aortic dilatation rate, and only in younger persons with MFS. Finally, persons with high OSA risk were more likely to have had prior aortic root replacement, and loud snoring, age and male sex were the OSA risk factors most closely associated with this outcome. In the discussion below, we will place our findings in the context of prior studies, and address potential

Table 3 Association of STOP-BANG obstructive sleep apnoea risk factors and aortic dimensions

\begin{tabular}{|c|c|c|c|c|c|c|}
\hline \multirow[b]{2}{*}{ Outcome } & \multicolumn{3}{|c|}{ Aortic diameter, $\mathrm{mm}(\mathrm{n}=46)$} & \multicolumn{3}{|c|}{ Aortic dilatation, $\mathrm{mm}(\mathrm{n}=31)$} \\
\hline & B & SE & $\mathbf{P}$ & B & SE & $\mathbf{P}$ \\
\hline Loud snoring & 4.12 & 1.64 & 0.015 & 1.65 & 1.18 & 0.173 \\
\hline Tiredness & -0.71 & 1.54 & 0.646 & -0.31 & 1.05 & 0.780 \\
\hline Witnessed apnoeas & 3.36 & 2.58 & 0.199 & -1.40 & 1.67 & 0.405 \\
\hline Hypertension & 0.67 & 1.82 & 0.713 & 0.19 & 1.15 & 0.870 \\
\hline $\begin{array}{l}\text { Body mass index }(\geq 35 \mathrm{~kg} / \\
\left.\mathrm{m}^{2}\right)\end{array}$ & -7.11 & 3.49 & 0.048 & -0.14 & 0.12 & 0.256 \\
\hline Age ( $\geq 50$ years) & 5.03 & 2.20 & 0.027 & -1.48 & 1.61 & 0.363 \\
\hline Neck size $(\geq 40 \mathrm{~cm})$ & -1.78 & 2.36 & 0.458 & -1.97 & 1.52 & 0.214 \\
\hline Male sex & 3.95 & 1.40 & 0.007 & 1.87 & 0.93 & 0.053 \\
\hline
\end{tabular}


Table 4 Association of STOP-BANG obstructive sleep apnoea risk and aortic dilatation stratified by median age

Aortic dilatation, $\mathrm{mm}$

$\leq 30$ years of age

\begin{tabular}{llllllll}
\cline { 2 - 3 } Outcome & $\mathbf{B}$ & $\mathbf{S E}$ & $\mathbf{P}$ & & $\mathbf{B}$ & $\mathbf{S E}$ & $\mathbf{P}$ \\
\hline Loud snoring & 4.00 & 1.57 & 0.024 & -0.67 & 1.45 & 0.643 \\
\hline Tiredness & -0.06 & 1.53 & 0.968 & -0.64 & 1.35 & 0.657 \\
Witnessed apnoeas & -2.66 & 2.97 & 0.386 & -0.10 & 1.86 & 0.948 \\
\hline Hypertension & 2.35 & 2.15 & 0.292 & -0.17 & 1.24 & 0.918 \\
\hline Body mass index & -0.34 & 0.21 & 0.133 & 0.03 & 0.15 & 0.832 \\
\hline Age & -0.31 & 0.16 & 0.074 & -0.67 & 1.45 & 0.391 \\
Neck size $(\geq 40 \mathrm{~cm})$ & -3.67 & 3.05 & 0.274 & -0.78 & 1.84 & 0.900 \\
Male sex & 2.25 & 1.37 & 0.122 & 0.21 & 1.46 & 0.897 \\
\hline
\end{tabular}

mechanisms, limitations and clinical implications of our study.

Kohler et al, has previously shown that persons with MFS and OSA have greater aortic diameter compared with those without OSA. ${ }^{9}$ We not only observed a similar cross-sectional association, but also found that high OSA risk was associated with aortic root dilatation. Our findings further suggested interactions between age and high OSA risk, particularly loud snoring, on aortic root dilatation. For example, aortic dilatation in loud snorers was higher among the younger but not older MFS participants, which may be due to a 'ceiling effect' of reduced aortic distensibility with increasing age, ${ }^{18}$ or the fact that most of the older snorers had already undergone aortic root replacement (figure 2). Furthermore, high OSA risk was strongly associated with aortic root replacement, which could reflect a mechanistic link of OSA with aortic disease progression or other considerations such as age and male sex aligned with OSA prompting surgical intervention. In fact, our evaluation of OSA risk factors and potential modifiers of aortic disease revealed age and male sex to be associated with prior aortic root replacement (table 5). Age and male sex may be important factors in the association between snoring/OSA risk and aortic disease, since both are risk factors for snoring/

Table 5 Association of obstructive sleep apnoea risk and prior aortic root replacement

\begin{tabular}{lllc}
\hline & B & 95\% Cl & P value \\
\hline Loud snoring & 2.65 & 1.01 to 7.08 & 0.048 \\
\hline Tiredness & 1.23 & 0.48 to 3.31 & 0.670 \\
Witnessed apnoeas & 1.42 & 0.34 to 5.43 & 0.614 \\
Hypertension & 1.75 & 0.60 to 4.98 & 0.298 \\
Age $(\geq 50$ years) & 9.90 & 3.47 to 31.15 & $<0.001$ \\
Body mass index & 1.04 & 0.05 to 11.32 & 0.976 \\
$\begin{array}{l}\left.\text { ( } 35 \mathrm{~kg} / \mathrm{m}^{2}\right) \\
\text { Neck size }(\geq 40 \mathrm{~cm})\end{array}$ & 2.22 & 0.53 to 9.31 & 0.268 \\
\hline Male sex & 3.52 & 1.40 to 9.24 & 0.009 \\
\hline
\end{tabular}

$\mathrm{OSA}^{19}$ and also for progression of aortic pathology ${ }^{20}$ in MFS.

Kohler et al also showed that persons with MFS with OSA were more likely to have aortic adverse events, ${ }^{21}$ supporting the findings of this study. Taken together, our findings suggest that OSA may either cause or predict aortic enlargement and aortic disease progression in selected persons with MFS.

Associations between OSA and aortic disease in MFS may be driven by the development of markedly negative nocturnal swings in inspiratory intrathoracic pressure that occur with upper airway obstruction. In fact, inspiring against an obstructed airway exerts substantial mechanical stress on intrathoracic tissues. ${ }^{22}$ As intrathoracic pressure falls, the aortic transmural pressure rises, which can accelerate aortic dilation and aneurysm formation. ${ }^{23} 24$ The magnitude of these pressure swings increases with the severity of OSA, sometimes exceeding $80 \mathrm{~mm} \mathrm{Hg}{ }^{22}$ Our study demonstrates that deleterious aortic outcomes are associated with both the severity and duration of UAO, as loud snoring in our subjects was likely associated with marked increases in snoring frequency and inspiratory duty cycle, ${ }^{11}$ thereby increasing the duration and severity of mechanical stress on the aorta. In addition to large intrathoracic pressure swings, OSA is characterised by recurrent arousals and concomitant surges in sympathetic activity. Cyclic elevations in pulse rate and blood pressure ensue ${ }^{71025}$ that can augment stress to the aorta.

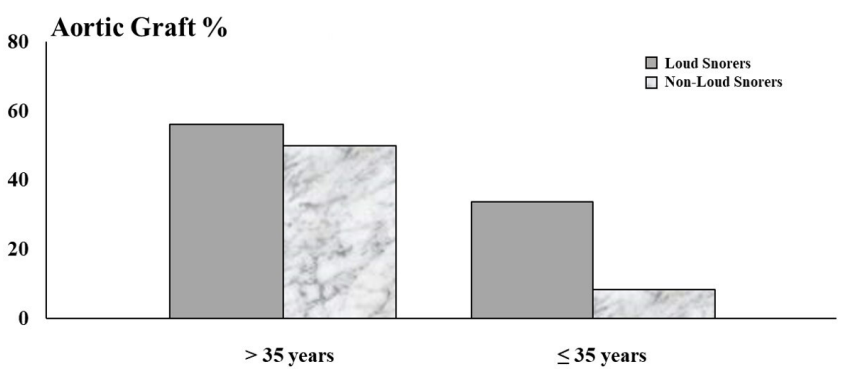

Figure 2 Proportion of subjects with aortic grafts stratified by median age. 


\section{Limitations}

We acknowledge several limitations in interpreting our findings. First, the sample size of this study was limited, preventing robust exploration of OSA risk factors and other potential modifiers of aortic dimensions in multivariable models. Nevertheless, our sample was substantial for a rare disorder like MFS and several levels of analyses in our sample confirmed the strong associations between loud snoring, a specific marker of OSA, and aortic outcomes including diameter, dilatation and presence of grafts. Second, our study lacked diagnostic validation for OSA risk from objective sleep studies. Sleep studies could provide objective measures of snoring, intrathoracic mechanical stress and surges in sympathetic activity from OSA. Future efforts should therefore assess aortic dilatation before and after treatment of validated sleep apnoea. Third, we could not determine the exact indications for aortic replacement surgery with grafting (beyond aortic enlargement itself). Fourth, we did not have sufficient sample data on genotype to determine whether OSA severity was related to differences in the autosomal dominant mutations in $F B N-1$, haploinsufficient versus dominant negative, which are known to modify the presence and severity of aortic disease in MFS. ${ }^{26}{ }^{27}$ Finally, we did not account for phenotypic complications of MFS including the presence of pectus deformity, scoliosis, kyphosis and comorbidities such as valvular heart disease, heart failure, asthma and chronic obstructive pulmonary disease (COPD) that may also modify the association of OSA and aortic disease progression.

\section{Clinical implications}

Functional defects in the $F B N-1$ protein leads to connective tissue pathology and vulnerability of the aortic wall in MFS. ${ }^{12}$ These defects cause soft tissue laxity that weaken the aortic wall and predispose to rapid aortic dilation over time. ${ }^{28}{ }^{29}$ However, additional factors may act as a 'second hit', effectively aggravating aortic pathology in MFS, as explained above. Our findings suggest that OSA should be further examined as such a pathogenic factor. Our findings carry additional importance because MFS may itself predispose to OSA through effects on palatal and pharyngeal structures. ${ }^{29-32}$ Despite the potential link between OSA and aortic disease progression in MFS, we recognise that OSA and aortic enlargement could be independent manifestations of underlying MFS disease severity.

We recently demonstrated accurate OSA screening in persons with MFS who had home sleep studies using the STOP-BANG questionnaire. ${ }^{33}$ As shown in this study, screening with the STOP-BANG questionnaire could serve as a simple means to stratify MFS persons for sleep phenotypes that might impact cardiovascular status. We do not believe that a high OSA risk finding with the STOPBANG replaces a valid sleep study; instead we believe that this screening approach may provide a persuasive rationale for obtaining formal sleep studies in patients with
MFS who present with atypical symptoms. Future studies are needed to quantify the nocturnal haemodynamic stresses associated with snoring and OSA in persons with MFS, and to investigate the efficacy of interventions in a clinical trial or patient registry setting.

Acknowledgements We acknowledge the genetic counsellors at the Johns Hopkins Connective Tissue Disorders Clinic for their support and Mariah Chaney for assisting with collecting the data used for this project. We also thank Kathryn Carson of the Johns Hopkins Institute for Clinical and Translational Research (supported by grant number UL1 TR003098 from the National Centre for Advancing Translational Sciences, a component of the National Institutes of Health $(\mathrm{NIH})$ and the NIH Roadmap for Medical Research) for her advice on statistical analysis.

Contributors MS: conceived and designed project, was involved with data collection, data analyses and manuscript writing. GM: contributed to project design and data collection. HD, JJ and ARS: contributed substantially to manuscript writing. ERN: conceived and designed project, contributed to data analyses and manuscript writing. All authors discussed the results and contributed to the final manuscript. MS and ERN accepts full responsibility for the work and/or the conduct of the study, had access to the data, and controlled the decision to publish.

Funding The authors have not declared a specific grant for this research from any funding agency in the public, commercial or not-for-profit sectors.

\section{Competing interests None declared.}

Patient and public involvement Patients and/or the public were involved in the design, or conduct, or reporting, or dissemination plans of this research. Refer to the Methods section for further details.

Patient consent for publication Not applicable.

Ethics approval The IRB X committee of the Johns Hopkins Institutional Review Board.

Provenance and peer review Not commissioned; externally peer reviewed. Data availability statement Data are available upon reasonable request.

Open access This is an open access article distributed in accordance with the Creative Commons Attribution Non Commercial (CC BY-NC 4.0) license, which permits others to distribute, remix, adapt, build upon this work non-commercially, and license their derivative works on different terms, provided the original work is properly cited, appropriate credit is given, any changes made indicated, and the use is non-commercial. See: http://creativecommons.org/licenses/by-nc/4.0/.

\section{REFERENCES}

1 Judge DP, Dietz HC. Marfan's syndrome. Lancet 2005;366:1965-76.

2 McKUSICK VA. The cardiovascular aspects of Marfan's syndrome: a heritable disorder of connective tissue. Circulation 1955;11:321-42.

$3 \mathrm{Koo} \mathrm{H-K}$, Lawrence KA, Musini VM. Beta-Blockers for preventing aortic dissection in Marfan syndrome. Cochrane Database Syst Rev 2017;11:CD011103.

4 Singh MN, Lacro RV. Recent clinical drug trials evidence in Marfan syndrome and clinical implications. Can J Cardiol 2016;32:66-77.

5 Aranson NJ, Patel PB, Mohebali J, et al. Presentation, surgical intervention, and long-term survival in patients with Marfan syndrome. J Vasc Surg 2020;72:480-9.

6 Schneider H, Schaub CD, Andreoni KA, et al. Systemic and pulmonary hemodynamic responses to normal and obstructed breathing during sleep. J Appl Physiol 1997;83:1671-80.

7 Stoohs R, Guilleminault C. Cardiovascular changes associated with obstructive sleep apnea syndrome. J Appl Physiol 1992;72:583-9.

8 Cistulli PA, Sullivan CE. Sleep-disordered Breathing in Marian's Syndrome. Am Rev Respir Dis 1993;147:645-8.

9 Kohler M, Blair E, Risby P, et al. The prevalence of obstructive sleep apnoea and its association with aortic dilatation in Marfan's syndrome. Thorax 2009;64:162-6.

10 Narkiewicz K, Wolf J, Lopez-Jimenez F, et al. Obstructive sleep apnea and hypertension. Curr Cardiol Rep 2005;7:435-40.

11 Sowho M, Sgambati F, Guzman M, et al. Snoring: a source of noise pollution and sleep apnea predictor. Sleep 2020;43:zsz305.

12 Rammohan HRS, Murthy K, Pressman GS. Effects of the Mueller maneuver on aortic area. Int J Cardiol 2014;173:128-9.

13 Cistulli PA, Wilcox I, Jeremy R, et al. Aortic root dilatation in Marfan's syndrome: a contribution from obstructive sleep apnea? Chest 1997;111:1763-6. 
14 Vanem TT, Geiran OR, Krohg-Sørensen K, et al. Survival, causes of death, and cardiovascular events in patients with Marfan syndrome. Mol Genet Genomic Med 2018;6:1114-23.

15 Barrios P, Martin-Biggers J, Quick V, et al. Reliability and criterion validity of self-measured waist, hip, and neck circumferences. BMC Med Res Methodol 2016;16:49.

16 Chung F, Abdullah HR, Liao P. Stop-Bang questionnaire: a practical approach to screen for obstructive sleep apnea. Chest 2016;149:631-8.

17 Muraru D, Maffessanti F, Kocabay G, et al. Ascending aorta diameters measured by echocardiography using both leading edgeto-leading edge and inner edge-to-inner edge conventions in healthy volunteers. Eur Heart J Cardiovasc Imaging 2014;15:415-22.

18 Jeremy RW, Huang H, Hwa J, et al. Relation between age, arterial distensibility, and aortic dilatation in the Marfan syndrome. Am J Cardiol 1994;74:369-73.

19 Chiu H-Y, Chen P-Y, Chuang L-P, et al. Diagnostic accuracy of the Berlin questionnaire, Stop-Bang, stop, and Epworth Sleepiness scale in detecting obstructive sleep apnea: a bivariate meta-analysis. Sleep Med Rev 2017;36:57-70.

20 Roman MJ, Devereux RB, Preiss LR, et al. Associations of age and sex with Marfan phenotype: the National heart, lung, and blood Institute GenTAC (genetically triggered thoracic aortic aneurysms and cardiovascular conditions) registry. Circ Cardiovasc Genet 2017; 10:e001647.

21 Kohler M, Pitcher A, Blair E, et al. The impact of obstructive sleep apnea on aortic disease in Marfan's syndrome. Respiration 2013;86:39-44.

22 Suzuki M, Ogawa $\mathrm{H}$, Okabe S, et al. Digital recording and analysis of esophageal pressure for patients with obstructive sleep apneahypopnea syndrome. Sleep Breath 2005;9:64-72.
23 Clarenbach CF, Camen G, Sievi NA, et al. Effect of simulated obstructive hypopnea and apnea on thoracic aortic wall transmural pressures. J Appl Physiol 2013;115:613-7.

24 Stöwhas A-C, Namdar M, Biaggi P, et al. The effect of simulated obstructive apnea and hypopnea on aortic diameter and bp. Chest 2011;140:675-80.

25 Ryan S. Mechanisms of cardiovascular disease in obstructive sleep apnoea. J Thorac Dis 2018;10:S4201-11.

26 Franken R, Teixido-Tura G, Brion M, et al. Relationship between fibrillin-1 genotype and severity of cardiovascular involvement in Marfan syndrome. Heart 2017;103:1795-9.

27 Franken R, Groenink M, de Waard V, et al. Genotype impacts survival in Marfan syndrome. Eur Heart J 2016;37:3285-90.

28 Perejda AJ, Abraham PA, Carnes WH, et al. Marfan's syndrome: structural, biochemical, and mechanical studies of the aortic media. $J$ Lab Clin Med 1985;106:376-83.

29 Hirata K, Triposkiadis F, Sparks E, et al. The Marfan syndrome: abnormal aortic elastic properties. J Am Coll Cardiol 1991;18:57-63.

30 da Palma RK, Farré R, Montserrat JM, et al. Increased upper airway collapsibility in a mouse model of Marfan syndrome. Respir Physiol Neurobiol 2015;207:58-60.

31 Cistulli PA, Sullivan CE. Sleep apnea in Marfan's syndrome. Increased upper airway collapsibility during sleep. Chest 1995;108:631-5.

32 Cistulli PA, Gotsopoulos H, Sullivan CE. Relationship between craniofacial abnormalities and sleep-disordered breathing in Marfan's syndrome. Chest 2001;120:1455-60.

33 Sowho MO, Patil S, Schneider $\mathrm{H}$, et al. Sleep disordered breathing in Marfan syndrome: value of standard screening questionnaires. Mol Genet Genomic Med 2020;8:e1039. 